Corrected: Publisher correction

ARTICLE

DOI: $10.1038 /$ s41467-018-06915-6

OPEN

\title{
All-inorganic cesium lead iodide perovskite solar cells with stabilized efficiency beyond 15\%
}

Kang Wang ${ }^{1}$, Zhiwen Jin ${ }^{1,2}$, Lei Liang ${ }^{1}$, Hui Bian¹, Dongliang Bai ${ }^{1}$, Haoran Wang ${ }^{1}$

Jingru Zhang ${ }^{1}$, Qian Wang ${ }^{1,2} \&$ Shengzhong Liu'1,3

As the black cesium lead iodide $\left(\mathrm{CsPb}_{3}\right)$ tends to transit into a yellow $\delta$-phase at ambient, it is imperative to develop a stabilized black phase for photovoltaic applications. Herein, we report a distorted black $\mathrm{CsPbl}_{3}$ film by exploiting the synergistic effect of hydroiodic acid $(\mathrm{HI})$ and phenylethylammonium iodide (PEAI) additives. It is found that the $\mathrm{HI}$ induces formation of hydrogen lead iodide $\left(\mathrm{HPbl}_{3+\mathrm{x}}\right)$, an intermediate to the distorted black phase with appropriate band gap of $1.69 \mathrm{eV}$; while PEAI provides nucleation for optimized crystallization. More importantly, it stabilizes the distorted black phase by hindering phase transition via its steric effects. Upon optimization, we have attained solar cell efficiency as high as $15.07 \%$. Specifically, the bare cell without any encapsulation shows negligible efficiency loss after $300 \mathrm{~h}$ of light soaking. The device keeps $92 \%$ of its initial cell efficiency after being stored for 2 months under ambient conditions.

\footnotetext{
${ }^{1}$ Key Laboratory of Applied Surface and Colloid Chemistry, Ministry of Education, Shaanxi Key Laboratory for Advanced Energy Devices, Shaanxi Engineering Lab for Advanced Energy Technology, School of Materials Science \& Engineering, Shaanxi Normal University, 710119 Xi'an, People's Republic of China. ${ }^{2}$ School of Physical Science and Technology \& Key Laboratory for Magnetism and Magnetic Materials of MoE, Lanzhou University, Lanzhou 730000 , People's Republic of China. ${ }^{3}$ Dalian National Laboratory for Clean Energy, iChEM, Dalian Institute of Chemical Physics, Chinese Academy of Sciences, 116023 Dalian, People's Republic of China. Correspondence and requests for materials should be addressed to

Z.J. (email: jinzhiwen@snnu.edu.cn) or to Q.W. (email: wangqian16@snnu.edu.cn) or to S.L. (email: szliu@dicp.ac.cn)
} 
T here have been incredible developments in organicinorganic hybrid lead halide perovskite solar cells (PSCs) recently. In fact, their power conversion efficiency (PCE) has skyrocketed from 3.8 to $22.7 \%$ in just a few years ${ }^{1-5}$. Unfortunately, the hybrid perovskite suffers from unavoidable degradation because the hydrogen-bonding between its monovalent organic cation and octahedral $\mathrm{PbI}_{2}$ is very weak ${ }^{6-10}$. It degrades to $\mathrm{PbI}_{2}$ under common external stresses, such as electric fields ${ }^{11,12}$, moisture ${ }^{13,14}$, photo-oxidation ${ }^{15,16}$, and UV irradiation $^{17}$. Substituting the organic cation by inorganic $\mathrm{Cs}^{+}$to fabricate an all-inorganic perovskite is effective for improved stability under these common stress conditions ${ }^{18,19}$. Unfortunately, the most ideal black $\alpha-\mathrm{CsPbI}_{3}$ (cubic phase) is thermodynamically less favorable. It spontaneously turns into an undesired $\delta-\mathrm{CsPbI}_{3}$ orthorhombic phase under ambient conditions ${ }^{20}$.

There has been extensive research into the preparation of $\mathrm{CsPbI}_{3}$ solar cells. For example, Snaith et al. ${ }^{20}$ fabricated the first $\mathrm{CsPbI}_{3}$ solar cell via an $\mathrm{HI}$ additive with the highest PCE of only $2.9 \%$. These trace amounts of HI were incorporated into the crystal lattice to form smaller grains with a distorted structure that stabilizes the cubic phase at room temperature. Luo et al. ${ }^{21}$ developed a new phase-transition scheme to fabricate $\alpha-\mathrm{CsPb}_{3}$ solar cells from $\mathrm{Cs}_{4} \mathrm{PbI}_{6}$ to increase the PCE to $4.13 \%$. Further advancement has been proven difficult, it has taken more than a year for the PCE to be slowly improved to $4.68 \%{ }^{22,23}$. Recently, vacuum-based vapor deposition was used to improve the PCE to $8.80 \%^{24,25}$. By accurately controlling the stoichiometric ratios of the precursors, Lin et al. ${ }^{26}$ and Troshin et al. ${ }^{27}$ increased PCEs to $9.40 \%$ and $10.5 \%$, respectively. Unfortunately, all of these devices showed very poor stability, even the well-encapsulated cells lasted for only a few days in an inert atmosphere. Thus, it is critical to improve the stability while increasing the initial PCE.

The size-dependent phase diagrams suggest that the cubic phase becomes more stable when the nano-crystal size is decreased ${ }^{28,29}$. In particular, Luther et al. fabricateda-CsPbI quantum dots (QDs) PSCs with a markedly improved PCE of $10.77 \%$. Excitingly, this solar cell remained stable for 60 days in a dry environment with no loss of $\mathrm{PCE}^{30}$. Furthermore, high mobility QD films were fabricated by passivating surface of the a$\mathrm{CsPbI}_{3}$ QDs using a halide salt with PCE of the corresponding solar cell being increased to $13.43 \%{ }^{31}$. More recently, long-chain ammonium additives were found to have a profound impact on the resulted material structure and stability ${ }^{32}$. For instance, Zhao et al. ${ }^{33}$ found that the $\mathrm{HPbI}_{3+x}$ intermediate facilitates the formation of $\alpha-\mathrm{CsPb}_{3}$ films at lower temperature, while the ethylenediamine cations help stabilize the black $\alpha-\mathrm{CsPbI}_{3}$ phase, making it possible to attain high cell efficiency of $11.8 \%$ with long-term stability for months. Kuang et al. ${ }^{34}$ introduced a bulky ammonium to form a stable two-dimensional $\mathrm{CsPbI}_{3}$-based PSC with a PCE of $4.84 \%$. The initial PCE of This sample decreased slightly after being aged under ambient condition for over 30 days. Later, by using sulfobetaine zwitterions to stabilize the $\alpha$ $\mathrm{CsPbI}_{3}$ film, Huang et al. ${ }^{35}$ developed PSCs with a PCE reaching up to $11.4 \%$ while it maintained $85 \%$ of its initial PCE after being stored in air exceeding 30 days.

The cubic phase can also be stabilized via partially substituting the $\mathrm{I}^{-}$with $\mathrm{Br}^{-}$ions ${ }^{36}$ to form $\mathrm{CsPbBr}_{x} \mathrm{I}_{3-x}{ }^{37-40}$. In particular, $\mathrm{CsPbBr}_{3}, \mathrm{CsPbBr}_{2} \mathrm{I}, \mathrm{CsPbI}_{2} \mathrm{Br}$, and $\mathrm{CsPbI}_{2+x} \mathrm{Br}_{1-x}$ have been used to fabricate PSCs with highly PCEs of $9.72 \%{ }^{41}, 8.02 \%^{42}, 14.81 \%$ 43 , and $14.4 \%^{44}$, respectively, with good phase stability over several months. Unfortunately, the $\mathrm{Br}^{-}$incorporation increases the band gap that is already too large for high-efficiency PSCs. It is also found that partial substitution of $\mathrm{Cs}^{+}$and $\mathrm{Pb}^{2+}$ with smaller radius metal cations also improves the stability ${ }^{45}$. In fact, solar cells based on $\mathrm{Cs}_{0.925} \mathrm{~K}_{0.075} \mathrm{PbI}_{2} \mathrm{Br}, \mathrm{CsPb}_{0.9} \mathrm{Sn}_{0.1} \mathrm{IBr}_{2}$,
$\mathrm{CsPb}_{0.96} \mathrm{Bi}_{0.04} \mathrm{I}_{3}$, and $\mathrm{CsPb}_{0.98} \mathrm{Mn}_{0.02} \mathrm{I}_{2} \mathrm{Br}$ also show respectable PCEs of $10.00^{46}, 11.33^{47}, 13.21^{48}$, and $13.47 \% \%^{49}$, respectively. In early 2013, based on theoretical calculations, Kanatzidis et al. ${ }^{50}$ proposed to use the distorted orthorhombic phase in perovskite solar cells. Later, Even et al..$^{51}$ and Snaith et al. ${ }^{52}$ discovered that lower-symmetry $\left(\beta-\mathrm{CsPb}_{3}\right.$ and $\left.\gamma-\mathrm{CsPbI}_{3}\right)$ perovskites show much lower phase-transition temperature $\left(260\right.$ and $175^{\circ} \mathrm{C}$, respectively) than the undistorted $\alpha-\mathrm{CsPbI}_{3}\left(360^{\circ} \mathrm{C}\right)$. These results suggest that the lower-symmetry perovskite orthorhombic black phase is beneficial to high stability devices ${ }^{53}$.

Herein, by mixing hydroiodic acid (HI) and phenylethylammonium iodine (PEAI) additives into the $\mathrm{CsPbI}_{3}$ precursor solution, we fabricate stabilized and distorted black phase-based $\mathrm{CsPbI}_{3}$ thin films with excellent crystallinity. To our surprise, the PCE of the $\mathrm{CsPbI}_{3}$ PSC is increased to $15.07 \%$-the highest yet reported for this type of inorganic perovskite cell. The performance is also remarkably stable under ambient conditions.

\section{Results}

Figure 1a shows the common yellow ( $\delta$-, Pnma) and black ( $\alpha-$, $\mathrm{Pm} 3 \mathrm{~m}$ ) phases of the $\mathrm{CsPbI}_{3}$ films. According to the phase diagram, the desired $\alpha-\mathrm{CsPbI}_{3}$ phase is stable only at high temperature (higher than $360^{\circ} \mathrm{C}$ ). The transition from the $\delta$-phase to the $\alpha$-phase indicates an obvious dynamic motion of the $\left[\mathrm{PbI}_{6 / 2}\right]^{-}$ octahedral ${ }^{51}$. Upon cooling, it is first converted into the distorted black perovskite $\beta-\mathrm{CsPb}_{3}(\mathrm{P} 4 / \mathrm{mbm}), \gamma-\mathrm{CsPbI} 3(\mathrm{Pbnm})$, and then to yellow $\delta$-CsPbI ${ }_{3}$ at 260,175 , and $25^{\circ} \mathrm{C}$, respectively. The four phases reported and their corresponding XRD patterns are given in Supplementary Fig. ${ }^{51}$. Note that the yellow $\delta$ phase consists of double-chains of non-corner-sharing $\left[\mathrm{PbI}_{6 / 2}\right]^{-}$octahedral, while the other three black phases show obviously corner-sharing $\left[\mathrm{PbI}_{6 / 2}\right]^{-}$octahedral ${ }^{53,54}$. Furthermore, the XRD peaks of the distorted phases $\left(\beta-\mathrm{CsPI}_{3}, \gamma-\mathrm{CsPbI}_{3}\right)$ are slightly splitted relative to the $\alpha-\mathrm{CsPbI}_{3}{ }^{55}$.

We fabricated a distorted black phase $\mathrm{CsPbI}_{3}$ by using a small amount of HI and PEAI (Fig. 1b). Here, the HI is reported to firstly form the hydrogen lead iodide $\left(\mathrm{HPbI}_{3+x}\right)$ intermediate with $\mathrm{PbI}_{2}$, which helps to grow the above-mentioned distorted phases $\left(\beta-\mathrm{CsPI}_{3}, \gamma-\mathrm{CsPbI}_{3}\right)^{33}$. The PEAI plays a dominant part in the nucleation and growth of the $\mathrm{CsPbI}_{3}$ film, in addition, it stabilizes the distorted black phase by hindering the phase transition through steric effects. For solar cell evaluation, a typical normal cell structure (glass substrate/fluorine-doped tin oxide (FTO)/ $\mathrm{TiO}_{2} / \mathrm{CsPbI}_{3} /$ Poly $[$ bis(4-phenyl) (2,4,6-trimethylphenyl)amine] $(\mathrm{PTAA}) / \mathrm{Au}$ ) was used (Fig. 1c). Figure 1d shows the energy level band diagram. The energy levels of each layer were measured as reported previously $\mathrm{y}^{39}$. The valence bands were obtained via ultraviolet photoelectron spectroscopy (UPS) ${ }^{56,57}$, and the conduction bands were estimated using the band gap derived from the optical absorption spectra.

A control film was synthesized using only PEAI without HI. It does not yield the dark perovskite phase even after annealing at $150^{\circ} \mathrm{C}$ for $3 \mathrm{~h}$. Therefore, we exclude it from the following discussion, and $\mathrm{HI}$ was used for all $\mathrm{CsPbI}_{3}$ films discussed below. The films prepared without the PEAI are termed as w/o PEAI, and the films with PEAI are labeled as $\mathrm{w}$ PEAI. In the present study, the amount of HI additive is further optimized to obtain larger grain size with desired film morphology. For this purpose, smaller amount of $\mathrm{HI}(100 \mu \mathrm{l})$ was used to carefully control the amount of $\mathrm{HPbI}_{3+x}$ formed to allow longer time of annealing at $150^{\circ} \mathrm{C}$ to achieve the optimal crystal growth. Microscopic imaging was used to examine the $\mathrm{CsPbI}_{3}$ films at each stage of growth and treatment.

Supplementary Figs. 2a, 3a show optical microscopy (OM) images with lower resolution photos as insets. Supplementary 
a

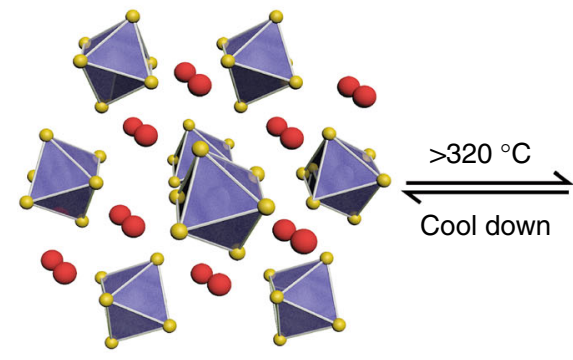

$\delta-\mathrm{CsPbl}_{3}$ orthorhombic phase

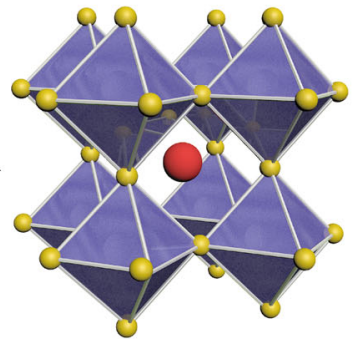

$\alpha-\mathrm{CsPbl}_{3}$ cubic phase b

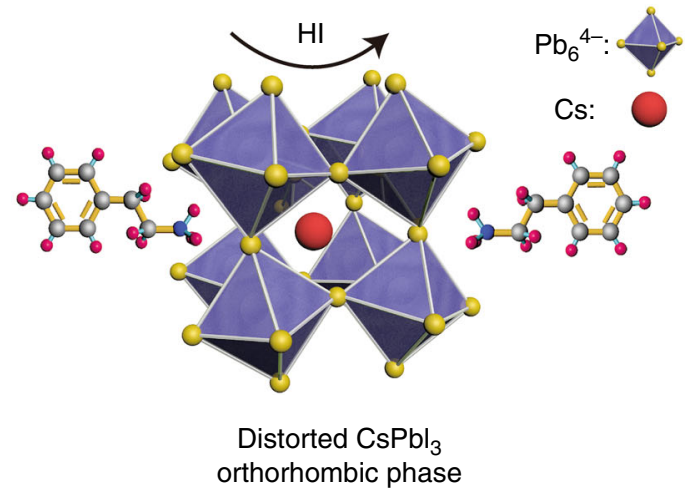

C

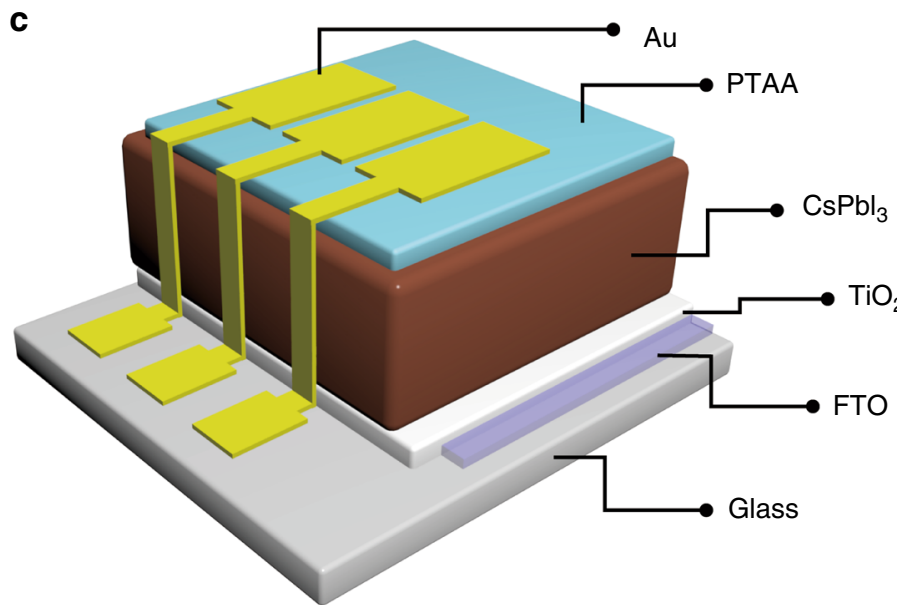

d

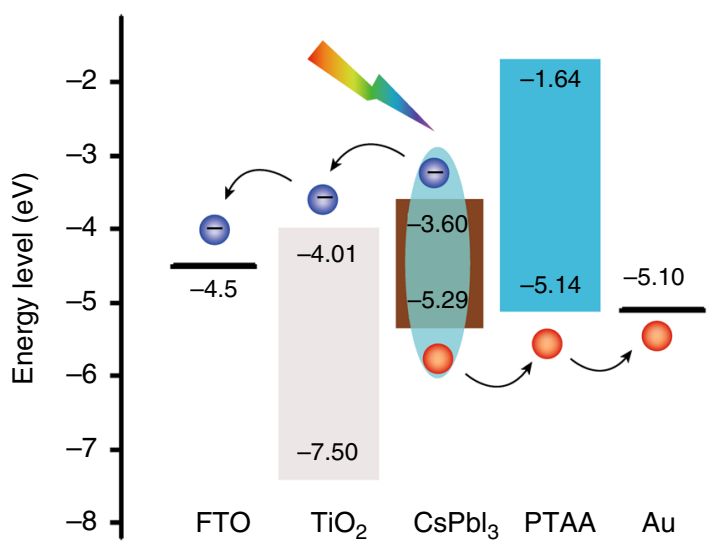

Fig. 1 Structure and energy level: a Schematic of common $\mathrm{CsPb}_{3}$ phases; $\mathbf{b} \mathrm{HI}$-induced and PEAl-stabilized distorted black $\mathrm{CsPb}_{3}$ orthorhombic phase; $\mathbf{c}$ Schematic device structure; d energy level

Figs. 2b, 3b present high-resolution scanning electron microscope (SEM) images of the sample surfaces. Supplementary Fig. 3c shows atomic force microscope (AFM) images for the samples prepared with PEAI annealed at $150{ }^{\circ} \mathrm{C}$ for different length of time up to $10 \mathrm{~h}$. Both films prepared with and without PEAI show small crystalline domain sizes of about $100 \mathrm{~nm}$, smooth surfaces, and yellow in color before annealing. The statistics of crystal size distributions are given in Supplementary Fig. 4. It is clear that the longer the annealing time, the larger the grain size. In other words, the grains grow larger during the annealing process.

We observed that the $\mathrm{CsPbI}_{3}$ film is formed rapidly upon the deposition of the precursor solution. With increasing the annealing time, the as-deposited yellow film quickly turns into black, with increased crystalline domain size, as shown in Supplementary Fig. 4. Without the PEAI additive, the blackest uniform sample was obtained after annealing for only $1 \mathrm{~h}$. Further heat treatment produces isolated yellow spots as shown in Supplementary Fig. 2a, suggesting that part of the sample has gone through a phase transition from the black phase to the yellow $\delta$ phase. As the process continues, the yellow spots became larger and larger, until they finally turn into a complete yellow film, identified to be the $\delta$ - $\mathrm{CsPbI}_{3}$ phase by X-ray diffraction (XRD) shown in Fig. 2. In comparison, when PEAI was used, it took up to $2 \mathrm{~h}$ of annealing before the black uniform film was completely formed, indicating that the $\mathrm{CsPbI}_{3}$ formation process is slower. Further heating beyond $2 \mathrm{~h}$ would result in yellow pinholes.

To gain insights into the phase transition mechanism, we measured optical absorption, XRD, and X-ray photoelectron spectroscopy (XPS). Figure 2a, c compares the absorption spectra of the $\mathrm{CsPb}_{3}$ films fabricated at different annealing time at $150^{\circ}$ C. It shows that the highest absorbance for the $\mathrm{CsPbI}_{3}$ films without and with PEAI occurred after annealing for 1 and $2 \mathrm{~h}$, respectively. Further annealing leads to decreased absorption intensities for the black phase, while the absorption peak at 420 $\mathrm{nm}$ for the $\delta$ - $\mathrm{CsPbI}_{3}$ phase increases, suggesting that the black $\mathrm{CsPbI}_{3}$ are partially transitioned into the yellow $\delta-\mathrm{CsPbI}$ phase. These results are consistent with the optical photographs. On the other hand, the surface elemental distributions of the films as analyzed using the XPS spectra (Supplementary Fig. 5) do not show any change with annealing time, indicating that the change in optical absorbance is due to evolution of the crystalline structure.

The XRD patterns were compared to the reference (Supplementary Fig. 1). There is no obvious difference between the films with and without PEAI before the annealing treatment. After annealing the sample for $1 \mathrm{~h}$, the $\mathrm{CsPbI}_{3}$ film prepared without PEAI shows optimum crystallization with surplus $\mathrm{HPbI}_{3+x}$ (Fig. 2b) ${ }^{58}$. As the annealing time is prolonged, the intensities of the distorted-phase-based $\mathrm{CsPbI}_{3}$ peaks decrease, and the $\delta$ $\mathrm{CsPbI}_{3}$ phase peaks start to appear. Finally, the film is transitioned completely into the $\delta$ - $\mathrm{CsPI}_{3}$ phase. In comparison, the $\mathrm{CsPbI}_{3}$ formed with PEAI (Fig. 2d) shows well defined peaks of distorted $\mathrm{CsPbI}_{3}$ phase after annealing for $2 \mathrm{~h}$, demonstrating that the PEAI did not alter the crystalline structure of the perovskite film. Furthermore, careful examination shows that the distorted black phase transited from $\beta$ to the $\gamma$ phase during the annealing process, as identified by the XRD peaks slowly shifting from $14.2^{\circ}$ to $14.3^{\circ}$ (Supplementary Fig. 6). 

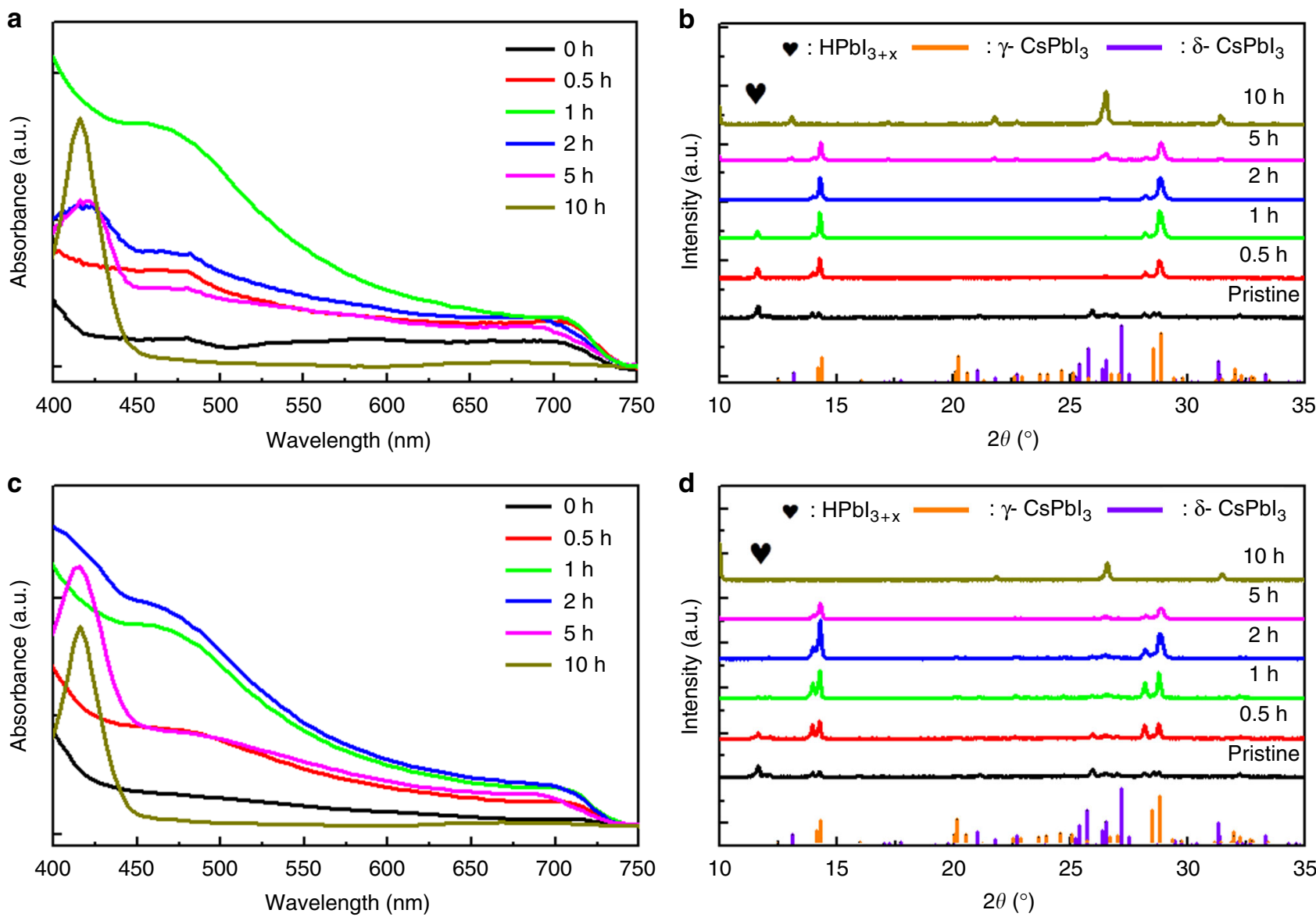

Fig. 2 Performance of the fabricated films: Comparison of the $\mathrm{CsPb}_{3}$ films without and with PEAl annealed at $150{ }^{\circ} \mathrm{C}$ for various times: $\mathbf{a}$, $\mathbf{c}$ optical absorption spectra; b, d XRD patterns

The effect of the PEAI was further studied by comparing the optimized distorted black phase-based $\mathrm{CsPbI}_{3}$ films deposited without and with PEAI. Cross-sectional SEM images (Supplementary Fig. 7a), UV-vis absorption spectra (Supplementary Fig. 7b), and photoluminescence (PL) spectra (Supplementary Fig. 7c) show that there is no obvious difference between the films prepared without and with the PEAI doping after they are annealed. Both films show same band gap of $1.69 \mathrm{eV}$, slightly lower than the value of $1.73 \mathrm{eV}$ as reported in literature ${ }^{59}$. X-ray photoelectron spectroscopy (XPS, Supplementary Fig. 7d) and the vertical composition profiles from the surface (Supplementary Fig. 8) show clear characteristic peaks assigned to $\mathrm{Cs} 3 d, \mathrm{~Pb} 4 f$, and I $3 d$, confirming that the added PEAI did not affect the composition of the films. Meanwhile, the other peaks show no change or shifting after adding the PEAI, indicating that the PEAI molecules bond to the surface of the crystal grain units only for the $\mathrm{PEA}^{+}$are too large to be inset into the $\mathrm{CsPbI}_{3}$ cages $^{53}$. Furthermore, the XRD results in Supplementary Fig. 7e show that the crystallization quality obviously improved by the PEAI additive. The orientation was obviously optimized as the XRD does not show peaks for (111), (020), and (120), likely because the $\mathrm{PEA}^{+}$ ions act as steric hindrance during the $\mathrm{CsPbI}_{3}$ crystal growth, leading to preferred orientation for (001), (110), (002), and (220). The energy-dispersive X-ray (EDX) analysis and contact angle measurements, shown in Supplementary Fig. 9 further confirm that PEAI is distributed uniformly in the grain boundary and surface.

Figure 3a presents a schematic diagram for the HI and PEAI additive-induced $\mathrm{CsPbI}_{3}$ crystalline growth. From the results, we infer that: (1) initially, $\mathrm{HI}$ reaction with $\mathrm{PbI}_{2}$ as intermediate $\mathrm{HPbI}_{3+x}$, and it creates distorted black phase-based $\mathrm{CsPbI}_{3}$ after combined with CsI during annealing at $150^{\circ} \mathrm{C}$. The results are consistent with previous studies ${ }^{58,60}$. (2) PEAI does not cause any change in the chemical composition of the final crystal structure, and likely plays only significant role in the nucleation and growth of $\mathrm{CsPb}_{3}$ films that lead to oriented crystal growth. (3) the PEAI acts as a blocking element to hinder the phase transition by bonding to the crystal units and through the steric effect. Supplementary Fig. 10 shows that the film without PEAI degraded within a few days for the black phase to transition to the yellow phase. Moreover, the PEAI based $\mathrm{CsPbI}_{3}$ film can retain the black color even after being heated at $80^{\circ} \mathrm{C}$ for $120 \mathrm{~h}$, while the reference film shows yellow spots in only $40 \mathrm{~h}$ (Supplementary Fig. 11). In summary, the distorted black phase-based $\mathrm{CsPbI}_{3}$ films obtained using the $\mathrm{HI}$ and PEAI additives show excellent properties, including large grain size, better thermal stability and lower band gap.

The thermal stability of the present $\mathrm{CsPbI}_{3}$ system was further confirmed by thermogravimetric analysis (TGA) and differential scanning calorimeter (DSC), as shown in Fig. $3 \mathrm{~b}$. When the sample is heated in nitrogen, no mass loss was observed until it gets from room temperature to $225^{\circ} \mathrm{C}$, at which point the film starts to decompose. The addition of PEAI is not found to have any detectable effect on thermal stability of the perovskite film (Supplementary Fig. 12) except that it starts to evaporate or decompose at about $300^{\circ} \mathrm{C}$. To confirm that the PEAI is indeed incorporated into the film, we examined the films (PEAI, $\mathrm{CsPbI}_{3}$, and $\mathrm{CsPb}_{3}$ film with PEAI) using the Fourier transform infrared 
a
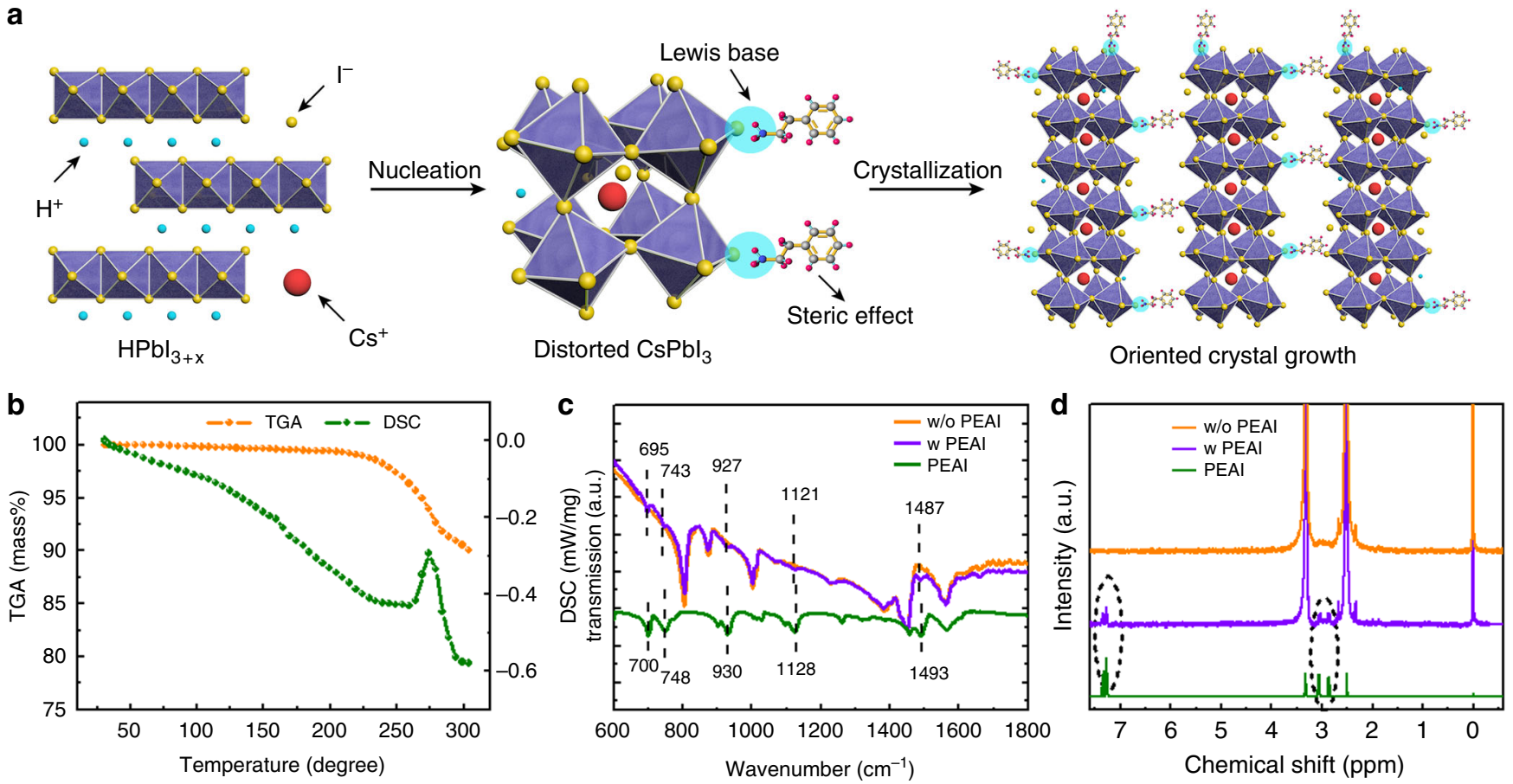

Fig. 3 Mechanism of HI/PEAI-induced phase stability: a Schematic for HI/PEAI additive-induced CsPbl 3 crystal growth. $\mathbf{b}$ TGA and DSC spectra for the $\mathrm{CsPbl}_{3}$ film with PEAI. c FTIR spectra, and $\mathbf{d}^{1} \mathrm{H}$ liquid-state NMR spectra for the related films

spectroscopy (FTIR, Fig. 3c). Clearly, the spectrum of the CsPbI film with PEAI shows absorption bands centered at 695, 743, 927, and $1121 \mathrm{~cm}^{-1}$ that are signatures of the benzene ring in the PEA + . Moreover, a peak at $1487 \mathrm{~cm}^{-1}$ is also resolved, ascribed to the $\mathrm{N}-\mathrm{H}$ scissor bending in the $\mathrm{PEA}^{+37}$. All these results attest the existence of $\mathrm{PEA}^{+}$in the $\mathrm{CsPbI}_{3}$ film. Meanwhile, careful comparison of the FTIR spectrum with that of the pure PEAI show that, all above peaks are shifted to smaller wavenumbers, demonstrating strong interaction between the functional groups of $\mathrm{PEA}^{+}$and $\mathrm{CsPbI}_{3}{ }^{61}$. We believe that one major reason is the chemical bonding between the PEAI and the $\mathrm{CsPbI}_{3}{ }^{33,62}$. To further prove that significant amount of $\mathrm{PEA}^{+}$is in the film, the nuclear magnetic resonance (NMR) measurement was conducted on the dissolved sample in deuterated DMSO- $\mathrm{d}_{6}$ solution (Fig. 3d). The pure PEAI gives two peaks at $\delta=7.3$ and $3 \mathrm{ppm}$, attributed to the benzene ring and its branched chain group, respectively. For the $\mathrm{CsPbI}_{3}$ film prepared with PEAI, the above two peaks shifted to downfield by $\Delta \delta \approx 0.1 \mathrm{ppm}$, indicating strong interaction between the $\mathrm{PEA}^{+}$and $\mathrm{CsPbI}_{3}{ }^{63}$.

Finally, the films based PSCs were fabricated to evaluate their photovoltaic performance. The current density $(J)$-voltage $(V)$ curves and photovoltaic parameters are presented in Supplementary Fig. 13 and Supplementary Table 1. Clearly, the optimal annealing conditions for the cells agree with the values reported above. The results for the $\mathrm{CsPbI}_{3}$ films (w/o PEAI) are shown in Supplementary Fig. 14. It shows a remarkable cell PCE of $11.50 \%$, with open-circuit voltage $\left(V_{\mathrm{OC}}\right)$ of $0.991 \mathrm{~V}$, short-circuit current density $\left(J_{\mathrm{SC}}\right)$ of $16.94 \mathrm{~mA} \mathrm{~cm}^{-2}$, and fill factor $(\mathrm{FF})$ of $68.6 \%$. The cell performance improves significantly when PEAI is introduced. When the film is optimized, the $V_{\mathrm{OC}}, J_{\mathrm{SC}}, \mathrm{FF}$, and PCE are 1.059 $\mathrm{V}, 18.95 \mathrm{~mA} \mathrm{~cm}^{-2}, 75.1$, and $15.07 \%$, respectively. Figure $4 \mathrm{a}$ presents typical $J-V$ curves measured using both reverse and forward scan directions with the key parameters summarized in the inset. It is clear that the $J-V$ curves measured using both scan directions overlap well with each other. In other words, the hysteresis of the present devices is negligible. It is known that the $V_{\mathrm{OC}}$ deficit which defined by $E_{\mathrm{g}} / q-V_{\mathrm{OC}}$ limits the PCE efficiencies ${ }^{64}$. Here, $E_{\mathrm{g}}$ is the optical band gap and $q$ electron charge. The $V_{\mathrm{OC}}$ deficit for our fabricated $\mathrm{CsPbI}_{3}$ PSCs is 0.631 $\mathrm{eV}$, larger than the best reported for organic-inorganic hybrid solar cells ${ }^{65}$, indicating to further increase device performance, reducing defect density in $\mathrm{CsPbI}_{3}$ layer or the interfaces are urgently expected.

The incident photon-to-electron conversion efficiency (IPCE) shows an integrated $J_{\mathrm{SC}}$ value of $18.86 \mathrm{~mA} \mathrm{~cm}^{-2}$ (Fig. $4 \mathrm{~b}$ ), which matches well with the value from the $J-V$ curve. Figure $4 \mathrm{c}$ presents the steady PCE versus time while being biased at the maximum power point $(0.86 \mathrm{~V})$; the champion device exhibits a very stable PCE and less than 3\% efficiency loss after $100 \mathrm{~h}$ of measurements. Long-term stability is critical for the perovskite solar cells. Figure $4 \mathrm{~d}$ shows that the device maintains $92 \%$ of its best PCE value after storage in air (relative humidity of 20 to $30 \%$ at about $25^{\circ} \mathrm{C}$ ) for over 60 days without any encapsulation. To test the light stability, the bare device without any encapsulation was placed under constant AM $1.5 \mathrm{G}$ illumination in a nitrogen filled glovebox for more than $300 \mathrm{~h}$. The device had negligible efficiency loss (Supplementary Fig. 15) demonstrating its steadiness to the light irradiation.

The PCE distribution for a batch of 50 solar cells is also shown in Fig. 4e. The data demonstrate that the devices are highly reproducible with an average $\mathrm{PCE}$ of $14.6 \%$. The best $\mathrm{CsPbI}_{3}$ filmbased device prepared here without PEAI demonstrated poor stability with PCE degradation to $0.65 \%$ after storage in ambient environment for 8 days (Supplementary Fig. 14). We also compared the results to those of other reported $\mathrm{CsPbI}_{3}$ PSCs. Figure $4 \mathrm{f}$ plots PCE versus band gap for the previously reported high PCE PSCs formed using various processing methods ${ }^{18-33}$. Our device with a distorted black phase-based $\mathrm{CsPbI}_{3}$ achieved the best PCE.

\section{Discussion}

In conclusion, we report an all-inorganic perovskite film based on distorted black phase $\mathrm{CsPbI}_{3}$. By introducing $\mathrm{HI}$ and PEAI additives, a well crystallized black phase-based $\mathrm{CsPbI}_{3}$ film is 

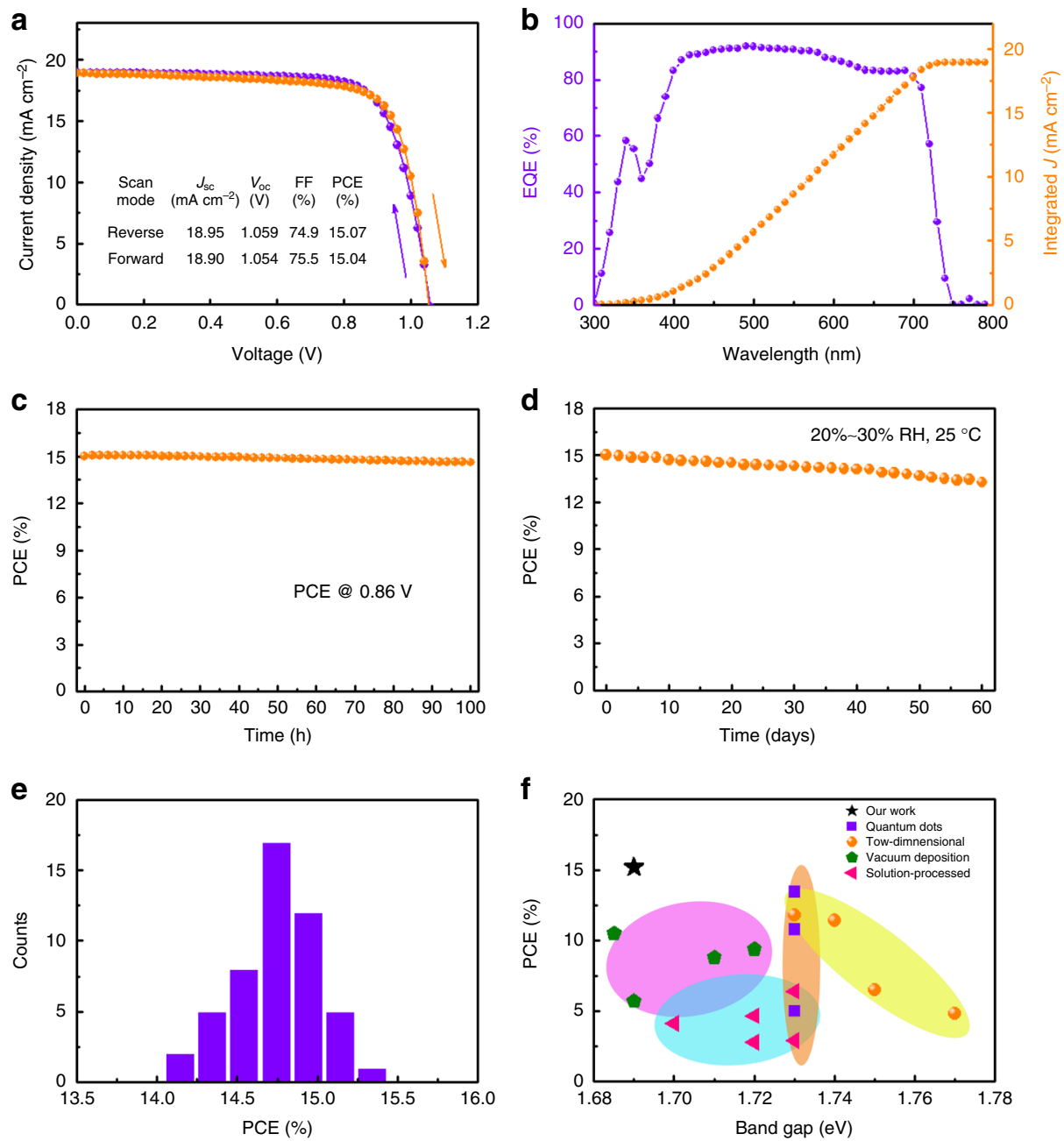

Fig. 4 Performance of the best device with PEAI: a J-V characteristics, b EQE, $\mathbf{c}$ steady-state measurement of the PCE, d long-term stability of the bestperforming device, e histogram of device efficiency distribution over 50 cells, and $\mathbf{f} \mathrm{PCE}$ distribution of $\mathrm{CsPb}_{3}$ PSCs as a function of band gap relative to published papers

produced. The optimized PSC shows a record PCE of $15.07 \%$ with remarkable stability. It is expected that these distorted black phase $\mathrm{CsPb}_{3}$ perovskites have significant potential applications in other optoelectronic devices in the future.

\section{Methods}

Precursor solutions preparation. The $\mathrm{CsPb}_{3}$ precursor solution used $\mathrm{HPbI}_{3+\mathrm{x}}$ $(0.88 \mathrm{~g})$ and CsI $(0.36 \mathrm{~g})$ dissolved in $2 \mathrm{ml} \mathrm{DMF/DMSO} \mathrm{(v/v} \mathrm{9:1)} \mathrm{in} \mathrm{N}_{2}$ atmosphere in a glovebox under active stirring for $24 \mathrm{~h}$. The $\mathrm{CsPb}_{3}-\mathrm{PEAI}$ precursor solution with $100 \mu \mathrm{l}$ PEAI DMF solution $\left(100 \mathrm{mg} \mathrm{ml}^{-1}\right.$ ) was then added to the above $\mathrm{CsPbI}_{3}$ precursor solution under active stirring for $6 \mathrm{~h}$. A HTL solution was prepared by dissolving PTAA ( $36 \mathrm{mg}$ ), a sulfonyl imide (Li-TFSI, $22 \mu \mathrm{l}, 520 \mathrm{mg}$ Li-TFSI in $1 \mathrm{ml}$ acetonitrile), and tert-butylpyridine (TBP, $36 \mu \mathrm{l})$ in $1 \mathrm{ml}$ of $\mathrm{CB}$ solution.

Device fabrication. A $25 \times 25 \mathrm{~mm}^{2}$ piece of clean FTO substrate was surface treated using an $\mathrm{O}_{2}$ plasma, and then the compact $\mathrm{TiO}_{2}$ layer coated on the FTO was formed by immersing $\mathrm{FTO}$ in a $40 \mathrm{mM} \mathrm{TiCl}{ }_{4}$ aqueous solution at $70^{\circ} \mathrm{C}$. Then, the $\mathrm{CsPb}_{3}$ layer was fabricated via spin-coating of the solution onto the substrate. Finally, the films were annealed at $150{ }^{\circ} \mathrm{C}$ for various time to form the films. PTAA layer was prepared by spin-coating the related precursor onto the $\mathrm{CsPbI}_{3}$ film. A 70-nm-thick gold electrode was then thermally evaporated onto the HTL-coated film.

Characterization. The film surface morphology and cross-sectional images were characterized by FESEM and EDS (Jeol SU-8020). The AFM images were acquired using a Veeco NanoScope IV with a silicon cantilever. Contact angles were measured on an OCA20 instrument (Data-physics). Absorbance spectra were collected using a Shimadzu UV-3600 double beam spectrometer. The PL spectra were measured using a PicoQuant FluoTime 300. The source light was a xenon short arc lamp. XRD patterns of the samples were measured using a Bruker D8 GADDS Diffractometer with the $\mathrm{Cu}$ Ka line. The XPS measurements were performed in a VG ESCALAB MK2 system with monochromatized Al Ka radiation. TGA/DSC was performed using a TGA Q50 (TA Instruments) and DSC Q2000 (TA Instruments), respectively. FTIR spectra observations of samples were carried out on a Bruker EQUINX55 spectrometer. Liquid-state NMR spectra were conducted on a VNMRS 600 instrument. The device active area was $0.1156 \mathrm{~cm}^{2}(3.4 \mathrm{~mm} \times 3.4$ $\mathrm{mm}$ ), and a mask with an aperture area of $0.09028 \mathrm{~cm}^{2}$ was used to prevent any scattered light or light piping to contribute to the photocurrent. The light source was performed via the solar simulator (SS-F5-3A, Enlitech) along with AM $1.5 \mathrm{G}$ spectra whose intensity was calibrated by the certified standard silicon solar cell (SRC-2020, Enlitech) at $100 \mathrm{~mW} \mathrm{~cm}-2 . J-V$ curves were measured using reverse scan mode (from $V_{\mathrm{OC}}$ to $I_{\mathrm{SC}}$ ) and forward scan mode (from $I_{\mathrm{SC}}$ to $V_{\mathrm{OC}}$ ) with a scan rate of $30 \mathrm{mV} \mathrm{s}^{-1}$. The spectral response was taken by an EQE measurement system (QE-R, Enlitech). The long-term stability was measured after storage in air (relative humidity of 20 to $30 \%$ at $25^{\circ} \mathrm{C}$ ) over 60 days without any encapsulation. To test the device light stability, we put the unencapsulated device in a nitrogen glovebox under constant AM 1.5G illumination.

\section{Data availability}

The data that support the findings of this study are available from the corresponding author upon reasonable request.

Received: 18 April 2018 Accepted: 26 September 2018 Published online: 31 October 2018 


\section{References}

1. Jiang, Q. et al. Enhanced electron extraction using $\mathrm{SnO}_{2}$ for high-efficiency planar-structure $\mathrm{HC}\left(\mathrm{NH}_{2}\right)_{2} \mathrm{PbI}_{3}$-based perovskite solar cells. Nat. Energy 2, 16177 (2016)

2. $\mathrm{Bi}$, C. et al. Non-wetting surface-driven high-aspect-ratio crystalline grain growth for efficient hybrid perovskite solar cells. Nat. Commun. 6, 7747 (2015).

3. $\mathrm{Wu}, \mathrm{Y}$. et al. Perovskite solar cells with $18.21 \%$ efficiency and area over $1 \mathrm{~cm}^{2}$ fabricated by heterojunction engineering. Nat. Energy 1, 16148 (2016).

4. Zhang, X. et al. Graphdiyne quantum dots for much improved stability and efficiency of perovskite solar cells. Adv. Mater. Interfaces 5, 1701117 (2018).

5. Jiang, J. et al. $\mathrm{CsPCl}_{3}$ driven low-trap-density perovskite grain growth for $>20 \%$ solar cell efficiency. Adv. Sci. 5, 1800474 (2018).

6. Giordano, F. et al. Enhanced electronic properties in mesoporous $\mathrm{TiO}_{2}$ via lithium doping for high-efficiency perovskite solar cells. Nat. Commun. 7, 10379 (2016).

7. Svane, K. L. et al. How strong is the hydrogen bond in hybrid perovskites? J. Phys. Chem. Lett. 8, 6154-6159 (2017).

8. $\mathrm{Li}, \mathrm{B}$. et al. Constructing water-resistant $\mathrm{CH}_{3} \mathrm{NH}_{3} \mathrm{PbI}_{3}$ perovskite films via coordination interaction. J. Mater. Chem. A 4, 17018-17024 (2016).

9. Feng, J. et al. E-beam evaporated $\mathrm{Nb}_{2} \mathrm{O}_{5}$ as an effective electron transport layer for large flexible perovskite solar cells. Nano Energy 36, 1-8 (2017)

10. Jin, Z. et al. Solution-processed transparent coordination polymer electrode for photovoltaic solar cells. Nano Energy 40, 376-381 (2017).

11. Leijtens, T. et al. Mapping electric field-induced switchable poling and structural degradation in hybrid lead halide perovskite thin films. Adv. Energy Mater. 5, 1500962 (2015)

12. Bae, S. et al. Electric-field-induced degradation of methylammonium lead iodide perovskite solar cells. J. Phys. Chem. Lett. 7, 3091-3096 (2016)

13. Wang, F. et al. Phenylalkylamine passivation of organolead halide perovskites enabling high-efficiency and air-stable photovoltaic cells. Adv. Mater. 28, 9986-9992 (2016).

14. Jiang, J. et al. Polymer doping for high-efficiency perovskite solar cells with improved moisture stability. Adv. Energy Mater. 8, 1701757 (2018).

15. Huang, H. et al. Efficient and selective photocatalytic oxidation of benzylic alcohols with hybrid organic-inorganic perovskite materials. ACS Energy Lett. 3, 755-759 (2018)

16. Brennan, M. C., Draguta, S., Kamat, P. V. \& Kuno, M. Light-induced anion phase segregation in mixed halide perovskites. ACS Energy Lett. 3, 204-213 (2017).

17. Wang, Q. et al. Energy-down-shift $\mathrm{CsPbCl}_{3}: \mathrm{Mn}$ quantum dots for boosting the efficiency and stability of perovskite solar cells. ACS Energy Lett. 2, 1479-1486 (2017).

18. Chen, H. et al. Inorganic perovskite solar cells: a rapidly growing field. Sol. RRL 2, 1700188 (2018)

19. Sim, K. M., Swarnkar, A., Nag, A. \& Chung, D. S. Phase stabilized $a-\mathrm{CsPb}_{3}$ perovskite nanocrystals for photodiode applications. Laser Photonics Rev. 12, 1700209 (2018)

20. Eperon, G. E. et al. Inorganic caesium lead iodide perovskite solar cells. $J$. Mater. Chem. A 3, 19688-19695 (2015).

21. Luo, P. et al. Solvent engineering for ambient-air-processed, phase-stable $\mathrm{CsPbI}_{3}$ in perovskite solar cells. J. Phys. Chem. Lett. 7, 3603-3608 (2016)

22. Ripolles, T. S., Nishinaka, K., Ogomi, Y., Miyata, Y. \& Hayase, S. Efficiency enhancement by changing perovskite crystal phase and adding a charge extraction interlayer in organic amine free-perovskite solar cells based on cesium. Sol. Energy Mater. Sol. Cells 144, 532-536 (2016).

23. Sutton, R. J. et al. Bandgap-tunable cesium lead halide perovskites with high thermal stability for efficient solar cells. Adv. Energy Mater. 6, 1502458 (2016).

24. Hutter, E. M. et al. Vapour-deposited cesium lead iodide perovskites: microsecond charge carrier lifetimes and enhanced photovoltaic performance. ACS Energy Lett. 2, 1901-1908 (2017).

25. Yonezawa, K. et al. Annealing effects on $\mathrm{CsPbI}_{3}$-based planar heterojunction perovskite solar cells formed by vacuum deposition method. Jpn. J. Appl. Phys. 56, 04CS11 (2017).

26. Chen, C. Y. et al. All-vacuum-deposited stoichiometrically balanced inorganic cesium lead halide perovskite solar cells with stabilized efficiency exceeding 11\%. Adv. Mater. 29, 1605290 (2017).

27. Frolova, L. A. et al. Highly efficient all-inorganic planar heterojunction perovskite solar cells produced by thermal coevaporation of CsI and $\mathrm{PbI}_{2}$. J. Phys. Chem. Lett. 8, 67-72 (2017).

28. Zhang, X., Wang, Q., Jin, Z., Zhang, J. \& Liu, F. S. Stable ultra-fast broadbandwidth photodetectors based on alpha-CsPbI $\mathrm{Pb}_{3}$ perovskite and $\mathrm{NaYF}_{4}: \mathrm{Yb}$, Er quantum dots. Nanoscale 9, 6278-6285 (2017).

29. Wang, Q. et al. $\mu$-Graphene crosslinked $\mathrm{CsPbI}_{3}$ quantum dots for high efficiency solar cells with much improved stability. Adv. Energy Mater. 8, 1800007 (2018).
30. Swarnkar, A. et al. Quantum dot-induced phase stabilization of $a-\mathrm{CsPb}_{3}$ perovskite for high-efficiency photovoltaics. Science 354, 92-95 (2016).

31. Sanehira, E. M. et al. Enhanced mobility $\mathrm{CsPbI}_{3}$ quantum dot arrays for record-efficiency, high-voltage photovoltaic cells. Sci. Adv. 3, eaao4204 (2017).

32. Li, F. et al. Tailored dimensionality to regulate phase stability for inorganic cesium lead iodide perovskites. Nanoscale 10, 6318-6322 (2018).

33. Zhang, $\mathrm{T}$. et al. Bication lead iodide $2 \mathrm{D}$ perovskite component to stabilize inorganic $a-\mathrm{CsPI}_{3}$ perovskite phase for high-efficiency solar cells. Sci. Adv. 3 e1700841 (2017).

34. Liao, J.-F., Rao, H.-S., Chen, B.-X., Kuang, D.-B. \& Su, C.-Y. Dimension engineering on cesium lead iodide for efficient and stable perovskite solar cells. J. Mater. Chem. A 5, 2066-2072 (2017).

35. Wang, Q. et al. Stabilizing the $\alpha$-phase of $\mathrm{CsPbI}_{3}$ perovskite by sulfobetaine zwitterions in one-step spin-coating films. Joule 1, 371-382 (2017).

36. Zheng, X. et al. Improved phase stability of formamidinium lead triiodide perovskite by strain relaxation. ACS Energy Lett. 1, 1014-1020 (2016).

37. Zhang, $\mathrm{X}$. et al. All-ambient processed binary $\mathrm{Cs} \mathrm{PbBr}_{3}-\mathrm{Cs}_{2} \mathrm{~Pb}_{2} \mathrm{Br}_{5}$ perovskites with synergistic enhancement for high-efficiency $\mathrm{Cs}-\mathrm{Pb}-\mathrm{Br}$-based solar cells. ACS Appl. Mater. Interfaces 10, 7145-7154 (2018).

38. Ma, Q., Huang, S., Wen, X., Green, M. A. \& Ho-Baillie, A. W. Y. Hole transport layer free inorganic $\mathrm{CsPbIB}_{2}$ perovskite solar cell by dual source thermal evaporation. Adv. Energy Mater. 6, 1502202 (2016).

39. Zhang, J. et al. 3D-2D-0D interface profiling for record efficiency all-inorganic $\mathrm{CsPbBrI}_{2}$ perovskite solar cells with superior stability. Adv. Energy Mater. 8, 1703246 (2018).

40. Liu, C. et al. All-Inorganic $\mathrm{CsPb}_{2} \mathrm{Br}$ perovskite solar cells with high efficiency exceeding 13\%. J. Am. Chem. Soc. 140, 3825-3828 (2018).

41. Duan, J., Zhao, Y., He, B. \& Tang, Q. High-purity inorganic perovskite films for solar cells with $9.72 \%$ efficiency. Angew. Chem. Int. Ed. 57, 1-6 (2018).

42. $\mathrm{Li}, \mathrm{W}$. et al. Phase segregation enhanced ion movement in efficient inorganic CsPbIBr 2 solar cells. Adv. Energy Mater. 7, 1700946 (2017).

43. Bai, D. et al. Temperature-assisted crystallization for inorganic $\mathrm{CsPbI}_{2} \mathrm{Br}$ perovskite solar cells to attain high stabilized efficiency $14.81 \%$. Nano Energy 52, 408-415 (2018).

44. Bian, H. et al. Graded bandgap $\mathrm{CsPbI}_{2+\mathrm{x}} \mathrm{Br}_{1-\mathrm{x}}$ perovskite solar cells with a stabilized efficiency of 14.4\%. Joule 2, 1500-1510 (2018).

45. Swarnkar, A., Mir, W. J. \& Nag, A. Can B-site doping or alloying improve thermal- and phase-stability of all-inorganic $\mathrm{CsPbX}_{3}(\mathrm{X}=\mathrm{Cl}, \mathrm{Br}, \mathrm{I})$ perovskites? ACS Energy Lett. 3, 286-289 (2018).

46. Nam, J. K. et al. Potassium incorporation for enhanced performance and stability of fully inorganic cesium lead halide perovskite solar cells. Nano Lett. 17, 2028-2033 (2017).

47. Liang, J. et al. CsPb ${ }_{0.9} \mathrm{Sn}_{0.1} \mathrm{IBr}_{2}$ based all-inorganic perovskite solar cells with exceptional efficiency and stability. J. Am. Chem. Soc. 139, 14009-14012 (2017).

48. $\mathrm{Hu}, \mathrm{Y}$. et al. Bismuth incorporation stabilized $\mathrm{a}-\mathrm{CsPbI}$ for fully inorganic perovskite solar cells. ACS Energy Lett. 2, 2219-2227 (2017).

49. Bai, D. et al. Interstitial $\mathrm{Mn}^{2+}$-driven high-aspect-ratio grain growth for lowtrap-density microcrystalline films for record efficiency $\mathrm{CsPb}_{2} \mathrm{Br}$ solar cells. ACS Energy Lett. 3, 970-978 (2018).

50. Stoumpos, C. C., Malliakas, C. D. \& Kanatzidis, M. G. Semiconducting tin and lead iodide perovskites with organic cations: phase transitions, high mobilities, and near-infrared photoluminescent properties. Inorg. Chem. 52, 9019-9038 (2013).

51. Marronnier, A. et al. Anharmonicity and disorder in the black phases of cesium lead iodide used for stable inorganic perovskite solar cells. ACS Nano 12, 3477-3486 (2018).

52. Sutton, R. J. et al. Cubic or Orthorhombic? Revealing the crystal structure of metastable black-phase $\mathrm{CsPbI}_{3}$ by theory and experiment. ACS Energy Lett. 3, 1787-1794 (2018).

53. Fu, Y. et al. Selective stabilization and photophysical properties of metastable perovskite polymorphs of $\mathrm{CsPbI}_{3}$ in thin films. Chem. Mater. 29, 8385-8394 (2017).

54. Huang, Y., Yin, W.-J. \& He, Y. Intrinsic point defects in inorganic cesium lead iodide perovskite $\mathrm{CsPbI}_{3}$. J. Phys. Chem. C. 122, 1345-1350 (2018).

55. Laurita, G., Fabini, D. H., Stoumpos, C. C., Kanatzidis, M. G. \& Seshadri, R. Chemical tuning of dynamic cation off-centering in the cubic phases of hybrid tin and lead halide perovskites. Chem. Sci. 8, 5628-5635 (2017).

56. Jin, Z. et al. Graphdiyne: $\mathrm{ZnO}$ nanocomposites for high-performance UV photodetectors. Adv. Mater. 28, 3697-3702 (2016).

57. Jin, Z. et al. Graphdiyne: an efficient hole transporter for stable highperformance colloidal quantum dot solar cells. Adv. Funct. Mater. 26, 5284-5289 (2016).

58. Feng, W., Hui, Y., Haihua, X. \& Ni, Z. $\mathrm{HPbI}_{3}$ : a new precursor compound for highly efficient solution-processed perovskite solar cells. Adv. Funct. Mater. 25, 1120-1126 (2015). 
59. Xiang, S. et al. Highly air-stable carbon-based $\alpha-\mathrm{CsPb}_{3}$ perovskite solar cells with a broadened optical spectrum. ACS Energy Lett. 3, 1824-1831 (2018).

60. Wang, Y., Zhang, T., Xu, F., Li, Y. \& Zhao, Y. A facile low temperature fabrication of high performance $\mathrm{CsPb}_{2} \mathrm{Br}$ all-inorganic perovskite solar cells. Sol. RRL 2, 1700180 (2018).

61. Li, B. et al. Surface passivation engineering strategy to fully-inorganic cubic $\mathrm{CsPbI}_{3}$ perovskites for high-performance solar cells. Nat. Commun. 9, 1076 (2018).

62. Zhang, $\mathrm{T}$. et al. In situ fabrication of highly luminescent bifunctional amino acid crosslinked $2 \mathrm{D} / 3 \mathrm{D} \mathrm{NH} \mathrm{C}_{4} \mathrm{H}_{9} \mathrm{COO}\left(\mathrm{CH}_{3} \mathrm{NH}_{3} \mathrm{PbBr}_{3}\right)_{\mathrm{n}}$ perovskite films. Adv. Funct. Mater. 27, 1603568 (2017).

63. Ravi, V. K. et al. Origin of the substitution mechanism for the binding of organic ligands on the surface of $\mathrm{CsPbBr}_{3}$ perovskite nanocubes. J. Phys. Chem. Lett. 8, 4988-4994 (2017).

64. Zewen, X. \& Yanfa, Y. Progress in theoretical study of metal halide perovskite solar cell materials. Adv. Energy Mater. 7, 1701136 (2017).

65. Huang, J., Yuan, Y., Shao, Y. \& Yan, Y. Understanding the physical properties of hybrid perovskites for photovoltaic applications. Nat. Rev. Mater. 2, 17042 (2017).

\section{Acknowledgements}

This work was funded by the National Key Research and Development Program of China MOST (2017YFA0204800), Fundamental Research Funds for the Central Universities (GK201703026/GK201804002), National Natural Science Foundation of China

(61704099), Natural Science Foundation of Shaanxi Province (2018JQ6072), and the 111 Project (B14041).

\section{Author contributions}

The project was conceived, planned, and supervised by Z.J. K.W., Z.J. and Q.W. performed the experiments, data analysis, and experimental planning. The manuscript was written by K.W. and Z.J. L.L., H.B., D.B., H.W. and J.Z. performed the experiments and reviewed the manuscript. S.L. supervised the overall project, discussed the results, and contributed to the final manuscript.

\section{Additional information}

Supplementary Information accompanies this paper at https://doi.org/10.1038/s41467018-06915-6.

Competing interests: The authors declare no competing interests.

Reprints and permission information is available online at http://npg.nature.com/ reprintsandpermissions/

Publisher's note: Springer Nature remains neutral with regard to jurisdictional claims in published maps and institutional affiliations.

(c) (i) Open Access This article is licensed under a Creative Commons Attribution 4.0 International License, which permits use, sharing, adaptation, distribution and reproduction in any medium or format, as long as you give appropriate credit to the original author(s) and the source, provide a link to the Creative Commons license, and indicate if changes were made. The images or other third party material in this article are included in the article's Creative Commons license, unless indicated otherwise in a credit line to the material. If material is not included in the article's Creative Commons license and your intended use is not permitted by statutory regulation or exceeds the permitted use, you will need to obtain permission directly from the copyright holder. To view a copy of this license, visit http://creativecommons.org/ licenses/by/4.0/.

(C) The Author(s) 2018 